\title{
Diagnóstico molecular da toxoplasmose: revisão
}

\author{
Molecular diagnosis of toxoplasmosis: review
}

Alicia Kompalic-Cristo ${ }^{1,2,3}$; Constança Britto ${ }^{2}$; Octavio Fernandes ${ }^{3}$

\section{unitermos resumo}

Toxoplasmose

Toxoplasma gondii

Diagnóstico

PCR

A toxoplasmose infecta milhões de pessoas no mundo inteiro, sendo que a prevalência da infecção humana na maioria dos países está entre $40 \%$ e $50 \%$. No Brasil essa taxa aumenta até $80 \%$, dependendo da área estudada. Na maioria dos hospedeiros a infecção é assintomática. A mulher grávida com sorologia negativa pode contribuir para o incremento da morbidade, transmitindo o Toxoplasma gondii para o feto, através da placenta, se adquirir toxoplasmose aguda durante a gravidez. O diagnóstico da toxoplasmose aguda é baseado na detecção de lgM anti-Toxoplasma gondii circulante. A alta sensibilidade das técnicas sorológicas atuais trouxe a realidade da presença de lgM residuais confundindo muitas vezes o diagnóstico final. Nesse sentido, as técnicas moleculares, tais como a reação em cadeia da polimerase (PCR), podem ajudar a uma melhor interpretação do estado real da interação parasito/homem, embora sejam ainda pouco validadas para uso na rotina de diagnóstico laboratorial da toxoplasmose.
\end{abstract}

abstract

Toxoplasmosis infects millions of people worldwide. The prevalence of human infection in many countries is estimated in approximately $40 \%$ to $50 \%$. In Brazil this rate increases up to $80 \%$, depending on the studied area. The majority of human hosts present the infection as asymptomatic carriers. Serologically negative pregnant women may contribute to a higher morbidity of the disease due to parasite transmission to the fetus via placenta if acute toxoplasmosis is acquired during pregnancy. The diagnosis of acute toxoplasmosis has relied on the evidence of circulating anti-parasite IgM. The high sensitivity of the present serological techniques has brought results of residual IgM eventually confounding final diagnosis. In this scenario, the molecular techniques, such as the polymerase chain reaction $(P C R)$, may promote a better interpretation of the real status of human/parasite interaction, although they have not been extremely validated for routine use in the diagnosis of toxoplasmosis. key words

Toxoplasmosis

Toxoplasma gondii

Diagnosis

$P C R$

\section{Introdução}

O Toxoplasma gondii foi descoberto quase ao mesmo tempo por Nicolle e Manceaux, na Tunísia, e por Splendore, no Brasil, em 1908 ${ }^{(53,65)}$. É um protozoário intracelular, que pode parasitar os mais diversos tecidos de vários mamíferos e aves. Seu ciclo de vida é conhecido desde finais da década de 1960, embora muitos pormenores da infecção ainda precisem ser esclarecidos ${ }^{(4)}$.
A toxoplasmose é uma zoonose de distribuição universal que acomete milhões de pessoas no mundo. Em diversos países, têm sido descritas soroprevalências que variam de $15 \%$ a $85 \%$ na população humana ${ }^{(39)}$. Em crianças, a soroprevalência é relativamente baixa, aumentando de acordo com a idade, com a exposição a mais fatores de risco durante o transcorrer da vida ${ }^{(1,11,67)}$. No Brasil, a soroprevalência tem sido determinada entre

\footnotetext{
1. Professora de Parasitologia do Departamento de Medicina Preventiva y Social, Decanato de Medicina, Universidad Centroccidental Lisandro Alvarado, Barquisimeto, Venezuela 2. Pesquisadora associada do Departamento de Bioquímica e Biologia Molecular, Instituto Oswaldo Cruz da Fundação Oswaldo Cruz (FIOCRUZ), Rio de Janeiro.

3. Pesquisador titular do Departamento de Medicina Tropical, Instituto Oswaldo Cruz da FIOCRUZ; gestor médico diagnósticos da América.
} 
$50 \%$ e $80 \%{ }^{(11)}$. Em Recife essa taxa é de $64 \%$ e $79 \%{ }^{(13)}$; no Rio de Janeiro se observou uma soroprevalência de 79\%; em Manaus, de 71\%; em São Paulo, de 68\%; e entre indígenas brasileiros, variou de $52 \%$ a $65 \%$ (1).

A parasitose pode se apresentar de diversas formas no organismo humano, porém estudos sorológicos indicam que mais de $80 \%$ das infecções primárias por T. gondii são assintomáticas $^{(73)}$.

Para que a toxoplasmose congênita possa ocorrer, a infecção primária deve se apresentar durante a gravidez ${ }^{(6,}$ 17). Assim, a multiplicação dos taquizoítas pode ser acompanhada da infecção da placenta, levando à possibilidade de transmissão vertical. No feto, o parasito se aloja em células do sistema fagocítico-mononuclear, dando origem às estruturas intermediárias denominadas pseudocistos; espalha-se por via sangüínea ou linfática para qualquer órgão ou tecido, incluindo sistema nervoso central e olhos, pelos quais tem um tropismo maior ${ }^{(49)}$.

As mulheres com infecção crônica por T. gondii não contaminam seus filhos durante o período intra-uterino, e também não existem provas de que a toxoplasmose em etapa crônica seja causa de abortos. Os casos de reativação da infecção pelo T. gondii, causados por imunossupressão materna, poderiam levar à infecção do feto durante a gravidez ${ }^{(52)}$. O sucesso da infecção fetal depende de fatores como virulência do T. gondii, desenvolvimento placentário, idade gestacional e carga parasitária, entre outros ${ }^{(1)}$.

Durante o primeiro trimestre da gestação, a infecção pelo T. gondii pode levar a morte fetal. No segundo trimestre, pode ocasionar a chamada tétrade de Sabin, em que o feto apresenta hidrocefalia, com macro ou microcefalia (em $50 \%$ dos casos), retinocoroidite (em $90 \%$ dos pacientes com infecção), calcificações cerebrais (em 69\%) e retardo mental ou perturbações neurológicas (em $60 \%$ dos casos); o recém-nascido também pode apresentar lesões iniciais como nódulos miliares disseminados por todo o encéfalo, ou em torno de focos necróticos; os ventrículos cerebrais podem estar dilatados e as lesões cerebrais podem se calcificar. Do mesmo modo, outras alterações oculares ainda podem acontecer, como graus variáveis de degeneração e edema de retina, lesões vasculares da coróide, neurite óptica, microftalmo, nistagmo, estrabismo, entre outras. Entre as manifestações neurológicas podem ser citadas as perturbações psicomotoras, convulsões, opistótono, etc. As crianças que sobrevivem à toxoplasmose congênita são, na maioria das vezes, mentalmente retardadas ${ }^{(26)}$.

A manifestação clínica da toxoplasmose no momento do nascimento é infreqüente, porém é a forma mais grave de apresentação no neonato. Ela pode se apresentar como infecção generalizada, com hepato e esplenomegalia, miocardite, pneumonia, icterícia, num recém-nascido de aspecto prematuro, o que geralmente corresponde a infecções tardias durante a gravidez. As infecções congênitas, na sua maioria, são assintomáticas no momento do nascimento, porém a quase totalidade dos neonatos com tais doenças apresentam seqüelas em algum momento da vida, principalmente complicações de tipo ocular ou do sistema nervoso central. Muitos casos de retinocoroidite na vida adulta podem ser conseqüência de uma toxoplasmose congênita assintomática no momento do nascimento ${ }^{(6)}$.

O diagnóstico definitivo de toxoplasmose congênita pode ser difícil em crianças nascidas de mães nas quais foi diagnosticada ou suspeitada a infecção durante a gravidez. Materiais para investigação do parasito ou amostras de sangue seriadas podem não estar disponíveis e, em adição, o diagnóstico sorológico é complicado pela presença de IgG materna antitoxoplasma, a qual pode ser detectada no sangue da criança durante o primeiro ano de vida ${ }^{(48)}$.

A maior parte dos casos de toxoplasmose pós-natal ou adquirida não exibe um quadro clínico definido. Nos indivíduos imunocompetentes a parasitose costuma ser assintomática ${ }^{(12)}$ ou oligossintomática, enquanto nos pacientes imunocomprometidos (portadores de HIV, neoplasias, transplantados, entre outros) podem ocorrer quadros de gravidade variável, capazes de provocar a morte. É considerada uma das maiores causas de morbimortalidade em pacientes com síndrome de imunodeficiência adquirida (AIDS) $)^{(20,24,43)}$.

O sistema imunológico desenvolve imunidade humoral ativada pelo sistema complemento, preferencialmente com anticorpos lgM e lgA, no caso de transmissão oral mediada pela ingestão de oocistos maduros ${ }^{(12,19)}$, e posteriormente com IgG e IgE. A IgM aparece aproximadamente na primeira ou na segunda semana após a infecção, alcançando um pico em seis a oito semanas, quando então declina. Pode permanecer no paciente até quatro a seis meses após o início da infecção por T. gondii (etapa considerada aguda ou recente) ou persistir em títulos baixos por mais de 12 meses, sendo considerada IgM residual|(11). A IgG se encontra também presente desde o início da parasitose, porém não desaparece totalmente, mantendo níveis no soro por toda a vida, embora possam ser mais baixos. Essa etapa equivale à fase crônica ou latente da doença. Para se ter certeza do momento da infecção toxoplásmica em que se encontra um indivíduo, é necessária a realização de testes sorológicos que detectem anticorpos anti-T. gondii, 
do tipo $\lg \mathrm{M}$ e $\lg \mathrm{G}$, principalmente. A presença de altos níveis de $\lg G$, assim como a persistência de lgM durante períodos longos de tempo, complica a interpretação dos testes sorológicos e a discriminação entre casos agudos e crônicos $^{\text {s(11, 16, 38). }}$.

\section{Diagnóstico laboratorial}

A infecção pelo T. gondii pode ser diagnosticada indiretamente, através de métodos sorológicos, e diretamente, por reação em cadeia da polimerase (PCR), hibridação, isolamento e anatomopatologia(51).

\section{Sorologia}

O primeiro teste disponível para detectar anticorpos específicos anti-T. gondii foi a reação de Sabin-Feldman (dye test). Cinqüenta anos depois da sua descrição, ainda é considerado um teste de referência com taxas altas de sensibilidade e especificidade. Entretanto, a sua utilização tem sido restrita pelo uso obrigatório de toxoplasma vivo, o que traz graves problemas de biossegurança(5).

O sorodiagnóstico é vastamente usado nos exames de rotina da grávida para se prevenir a toxoplasmose congênita. Diferentes técnicas têm a propriedade de detectar esses anticorpos no sangue dos pacientes. Testes como imunofluorescência, hemoaglutinação, immunosorbent agglutination assay (ISAGA), enzyme-linked immunosorbent assay (ELISA) ou microparticle enzyme immunoassay (MEIA) têm papel principal no cenário do diagnóstico da infecção pelo T. gondii $(3,11,32,51,63)$. Têm sido evidentes certas limitações desses métodos, uma vez que são descritas falhas ao detectar $\lg \mathrm{G}$ e $\lg \mathrm{M}$ durante a fase ativa da infecção, e tem sido demonstrado que esses anticorpos podem não ser produzidos durante as primeiras semanas da parasitemia(50). Sendo assim, o risco de toxoplasmose congênita pode não ser detectado nesses casos.

Mais recentemente evidenciou-se que a avidez da $\lg G$ pelo antígeno de $T$. gondii (que mede a capacidade de ligação entre esse anticorpo e seu antígeno) medida pela afinidade funcional aumenta com o passar do tempo(47). Isso, segundo a opinião de vários autores, é um marcador informativo à medida que a baixa avidez da lgG poderia ser interpretada como indicador do diagnóstico de infecção toxoplásmica recente, em combinação com um painel de outros exames ${ }^{(51)}$, porém ainda é evidente uma extensa janela de valores indeterminados ${ }^{(27,59)}$.

De igual forma, o diagnóstico sorológico da toxoplas- mose é complicado em pacientes imunocomprometidos, fetos, recém-nascidos, receptores de órgãos transplantados e principalmente, em pacientes com AIDS. Nesses casos e nas gestantes com diagnóstico sorológico presuntivo de fase aguda, a detecção direta do parasito pode ser proposta ${ }^{(40,}$ 42). O surgimento do vírus da imunodeficiência humana (HIV) tem incrementado a necessidade de diagnósticos mais sensíveis e eficientes para infecções oportunistas. A toxoplasmose latente tem o risco de se transformar em encefalite toxoplásmica nesses pacientes ${ }^{(41,42)}$. Do mesmo modo, tem se incrementado a necessidade de diagnósticos precoces para detectar a reagudização de toxoplasmose latente em pacientes com outros tipos de imunossupressão, tais como câncer, transplante de órgãos e outras ${ }^{(45)}$.

\section{Isolamento}

$\mathrm{O}$ isolamento do parasito de sangue ou outros fluidos corporais demonstraria uma possível infecção aguda(51). Métodos tradicionais de detecção direta do parasito como diagnóstico inequívoco são dificilmente realizáveis nessa doença, devido à ampla disseminação do seu agente causal e ao seu tropismo por várias células do organismo humano, gerando negatividade repetida na pesquisa direta do toxoplasma $^{(1,57,72)}$. De igual forma, sabe-se que a parasitemia é detectável de forma intermitente em alguns pacientes ${ }^{(23,}$ $35,44)$. Por ser um parasito intracelular obrigatório, a cultura in vitro é complicada de ser mantida, tem custo elevado e necessita de longo tempo para fornecer resultado, muitas vezes só sendo efetiva em menos de $50 \%$ dos casos. $\mathrm{O}$ isolamento do parasito pode ser feito com a inoculação em camundongos, o que é mais sensível, porém requer de três a seis semanas e manutenção de animais em biotérios ${ }^{(29,}$ $33,39,45,50)$.

\section{Métodos moleculares}

Durante os últimos 15 anos, o diagnóstico de agentes infecciosos inclui o uso de tecnologia que envolve os ácidos nucléicos. O diagnóstico de organismos parasitários é o último campo da microbiologia clínica que incorporou essas técnicas, devido aos custos altos dos ensaios de biologia molecular e às baixas prevalências dessas infecções em países que estão na vanguarda da biotecnologia. A presença do parasito pode ser demonstrada através de seus componentes antigênicos ou de segmentos de DNA.

Em 1985, a estratégia para se amplificar um alvo genômico mediante a replicação do DNA in vitro foi descrita ${ }^{(61)}$. $O$ ensaio da PCR é uma técnica utilizada em testes clínicos para 
detecção de alterações genéticas ou infecções por diferentes agentes etiológicos ${ }^{(22)}$. Avanços recentes no conhecimento do genoma do $T$. gondii tornaram possível a utilização da PCR para a detecção do parasito ${ }^{(4,72)}$.

Amostras de sangue testadas para se investigar parasitemia por ensaios de PCR, amplificando-se segmentos dos genes B1 e P30 de T. gondii, mostraram o potencial da técnica para o diagnóstico não-invasivo da toxoplasmose

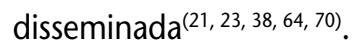

Diferentes pares de iniciadores para replicação in vitro dirigidos a diferentes alvos têm sido utilizados. O primeiro a ser testado e mais amplamente usado é o gene B1, que se encontra repetido em 35 cópias no genoma do protozoário parasito. Diversos grupos designaram vários iniciadores que se anelam em diferentes localizações do gene $^{(9,28,46,54,68,69) \text {. }}$

O gene $B 1$ possui um tamanho de 2,2Kb, foi isolado e descrito por Boothroyd et al. (1987), demonstrando ter uma natureza repetitiva no genoma. Burg et al. (1989) demonstraram a alta sensibilidade da PCR na deteç̧ão de apenas um parasito presente no lisado celular usando o gene B1 como alvo de amplificação. Junto a 100 mil células humanas, esses autores conseguiram detectar até um único parasito. Os resultados mostravam a alta especificidade do gene B1 do $T$. gondii e a característica de ser uma região conservada em todas as cepas testadas. Os resultados descritos sugerem que o DNA do parasito pode ser detectado diretamente do creme leucocitário. Recentemente ficou demonstrada a baixa especificidade desse sistema, uma vez que foi evidenciada a co-amplificação de outras seqüências-alvo nos cromossomos humanos. Não obstante, ainda continua sendo o alvo mais usado no diagnóstico de parasitemia ${ }^{(44)}$.

Em estudos citados por Wong e Remington (1993) e realizados por Thulliez et al., foi demonstrado que a sensibilidade e a especificidade da PCR amplificando o gene B1 de parasitos presentes no líquido amniótico foi de $100 \%$, em contraste com a inoculação de sangue fetal ou líquido amniótico em camundongos e culturas. A possibilidade de realizar a PCR para detectar T. gondii em sangue humano, como teste diagnóstico, tem sido descrita(38). Assim, a PCR revolucionou o diagnóstico pré-natal de toxoplasmose congênita, uma vez que limita o uso de métodos invasivos no feto ${ }^{(41,51,66)}$.

Um outro alvo também amplamente usado é o gene P30, que se encontra representado como cópia única codificando para o principal antígeno de superfície do protozoário. Diferentes pares de iniciadores foram igualmente propostos para esse gene ${ }^{(21,39,62,71)}$. Na literatura, protocolos que empregam a PCR convencional (qualitativa) para a deteç̧ão de genes em cópia única, como o gene P30, aparecem menos sensiveis ${ }^{(10)}$.

Outras seqüências-alvo também têm sido utilizadas como: 1) o gene codificante para o RNA da subunidade menor ribossômica, que se encontra repetido em 110 cópias por genoma; 2) um fragmento de $529 \mathrm{pb}$ presente em 200 a 300 cópias por célula; 3) os genes de cópia única codificantes para $\alpha$ e $\beta$ tubulina; e 4 ) um aparente segmento repetitivo de DNA não-codificante (TGR1E) $)^{(4,30,34,37)}$.

Diversos estudos demonstram a capacidade da PCR em amplificar fragmentos específicos de DNA a partir de fluidos corporais diferentes ${ }^{(2,57,70)}$, tais como sangue ${ }^{(4,5,9}$, $21,23,42,43,46,64,66)$, líquido amniótico ${ }^{(29,31,36,54)}$, liquor ${ }^{(20,66,69)}$, humor aquoso $\mathrm{o}^{(7,8,18)}$, fluido de lavado bronco-alveolar ${ }^{(60)} \mathrm{e}$ até urina ${ }^{(25)}$.

Por outro lado, a PCR só será positiva em casos de parasitemia; assim, em casos de toxoplasmose cerebral ou pulmonar, a PCR será de utilidade apenas quando houver disseminação ou passagem do parasito para o sangue, tal como ocorre na etapa aguda dessa parasitose ${ }^{(43)}$. Nos casos de baixa parasitemia pode ser o método de escolha, permitindo a detecção do parasito e apontando uma interpretação mais exata da etapa de infecção pelo T. gondii, indispensável para a prevenção do nascimento de uma criança com toxoplasmose congênita; assim como na terapia farmacológica e no apoio psicológico requerido por uma futura mãe com probabilidades de ter esse diagnóstico. Por outro lado, nos países nos quais o aborto terapêutico é permitido, abortos desnecessários poderiam ser evitados ${ }^{(39)}$.

Muitos autores têm avaliado a PCR como técnica de diagnóstico de encefalite toxoplásmica ${ }^{(14)}$, toxoplasmose pulmonar e até toxoplasmose congênita, usando diferentes protocolos, todos eles sugerindo estarem corretos e podendo ser indicados. Esses excitantes resultados sugerem que infecções fetais podem ser diagnosticadas cedo na gravidez, através da análise de líquido amniótico, sem a necessidade de obtenção de amostras de sangue fetal ou de procedimentos mais invasivos ${ }^{(56,73)}$.

Numerosos ensaios têm sido desenvolvidos, mas nenhum foi suficientemente otimizado e validado com um número grande de indivíduos $(4,44,70)$. Segundo Bastien (2002), o diagnóstico por PCR para a toxoplasmose está longe de ser padronizado e ainda não se tem um consenso que defina as condições do método. Além de outros fatores, a sensibilidade e a especificidade da PCR dependem não só da seqüência-alvo no DNA do parasito, mas também dos pares de iniciadores de amplificação desenhados. In- 
felizmente, pouco tem sido publicado para o Toxoplasma gondii na literatura nesse sentido. Apesar das raras propostas de PCR para o diagnóstico de toxoplasmose, elas não são consensuais, e mais comparações são necessárias para se conseguir uma melhor padronização.

A PCR em tempo real foi recentemente introduzida para o diagnóstico da toxoplasmose. Nessa metodologia são combinados os tempos de amplificação e detecção numa mesma fase ${ }^{(15,56)}$. A técnica pode ser usada para estimar a concentração de parasitos no fluido corporal e no caso de líquido amniótico é capaz de contribuir precocemente para o prognóstico da toxoplasmose congênita, ao permitir avaliar a concentração de parasitos no mesmo ${ }^{(56,58)}$. Com esse cenário, os resultados obtidos por Romand et al. (2004) mostram excelente relação entre carga parasitária, período da infecção materna e risco de infecção fetal, abrindo novas perspectivas para a valorização da PCR em tempo real como um ensaio que pode contribuir significantemente na orientação diagnóstica e terapêutica por parte dos obstetras e infectologistas ${ }^{(58)}$.

A PCR quantitativa também pode prover dados adicionais que auxiliam na escolha de tratamento específico. A carga parasitária pode ser determinada e relacionada com a sintomatologia e o tratamento. Esse exame é de utilidade para o monitoramento da eficácia do tratamento e pode ajudar no entendimento da patogênese da reativação da toxoplasmose ${ }^{(15)}$.

A PCR em tempo real é uma metodologia rápida, sensível e quantitativa de detecção do T. gondii em amostras clínicas. $O$ ensaio pode ser usado na rotina de laboratórios em combinação com testes sorológicos. É particularmente útil em pacientes com AIDS, uma vez que a capacidade destes em gerar IgM se encontra limitada, além da dificuldade encon- trada para a interpretação dos estudos sorológicos. Os ensaios quantitativos pela PCR parecem ser apropriados para o diagnóstico da toxoplasmose e o monitoramento terapêutico ${ }^{(15,58)}$. Porém mais estudos são necessários para explorar o potencial dessa técnica no diagnóstico da toxoplasmose ${ }^{(44,50)}$.

Apesar de todos esses esforços, pergunta-se ainda se o diagnóstico da toxoplasmose utilizando técnicas moleculares de amplificação de DNA é inequívoco. Relatos de pacientes IgM-negativos com PCR positivas estão presentes na literatura, desconfiando-se de falsa positividade ou se considerando parasitemia na fase crônica da doença ${ }^{(28)}$. Vários casos de PCR positivas em pacientes assintomáticos são referidos e se desconhece o valor preditivo positivo do teste ${ }^{(40,44,46)}$.

\section{Conclusões}

O diagnóstico da toxoplasmose é ainda hoje baseado na sorologia, e as técnicas moleculares se encontram em etapas recentes de avaliação. É muito cedo para determinar uma técnica padrão-ouro diferente da sorologia, uma vez que os diferentes sistemas descritos na literatura se mostram efetivos mas nem sempre reprodutíveis, ou com baixa especificidade.

Os métodos discutidos anteriormente têm nos auxiliado grandemente no diagnóstico da toxoplasmose. Porém, devem ser interpretados no contexto da situação clínica - história do paciente e sintomatologia - associados aos resultados dos outros exames realizados.

Falta muito ainda a percorrer nesse mundo da biologia molecular encaminhada à aplicação de uma técnica para o diagnóstico de uma parasitemia tão pouco conhecida como a produzida pelo Toxoplasma gondii.

\section{Referências}

I. AMENDOEIRA, M. R. R:; DA COSTA, T.; SPALDING, S. M. Toxoplasma gondii Nicolle \& Manceaux, 1909 (Apicomplexa: Sarcocystidae) e a Toxoplasmose. Revista Souza Marques, v. I, n. I, p. 15-35, 1999.

2. AMMASSARI, A. et al. AIDS-associated cerebral toxoplasmosis: an update on diagnosis and treatment. Curr Top Microbiol Immunol, v. 219, p. 209-222, 1996.

3. ASHBURN, D. et al. Do IgA, lgE, and lgG avidity tests have any value in the diagnosis of toxoplasma infection in pregnancy? J Clin Pathol, v. 5 I, p. 312-5, 1998.

4. BASTIEN, P. Diagnosis. Molecular diagnosis of toxoplasmosis. Trans R Soc Trop Med Hyg, v. 96, supl. I, p. 205- I 5, 2002.

5. BERGSTRÖM,T. et al. Congenital Toxoplasma gondii infection diagnosed by PCR amplification of peripheral mononuclear blood cells from a child and mother. Scand I Infec Dis, v. 30, p. 202-4, 1998.

6. BEVERLEY,J.K.A.A new look at infectious diseases. Toxoplasmosis. BrMed J, v. 2, p. 475-8, 1973.

7. BLANC-JOUVAN, M. et al. Chorioretinitis following liver transplantation: detection of Toxoplasma gondii in aqueous humor. Clin Infect Dis, v. 22, p. 184-5, 1996.

8. BOU, G. et al.Value of PCR for detection of Toxoplasma gondii in aqueous humor and blood samples from immunocompetent patients with ocular toxoplasmosis. J Clin Microbiol, v. 37, n. II, p. 3465-8, 1999.

9. BURG, J. L. et al. Direct and sensitive detection of a pathogenic protozoan, Toxoplasma gondii, by polymerase chain reaction. J Clin Microbiol, v. 27, n. 8, p. 1787-92, 1989. 
I0. BUCHBINDER, S.; BLATZ, R.; RODLOFF, A. C. Comparison of real-time $P C R$ detection methods for $\mathrm{BI}$ and $\mathrm{P} 30$ genes of Toxoplasma gondii. Diagn Microbiol Infect Dis, v. 45, p. 269-7I, 2003.

I I. CANTOS, G. A. et al. Toxoplasmose: ocorrência de anticorpos antiToxoplasma gondii e diagnóstico. Rev Ass Med Brasil, v. 46, n. 4, p. 335-4I, 2000

12. CARVALHO, C.M. C. N.; FARHAT, C. K.Acquired toxoplasmosis. J Pediatr, v. 75, supl. I, p. S63-S67, 1999.

I 3. COELHO, R.A. I.; KOBAYASHI, M.; CARVALHO, L. B. Prevalence of $\lg G$ antibodies specific to Toxoplasma gondii among blood donors in Recife, Northeast Brazil. Rev Inst Med Trop Sao Paulo, v. 45, n. 4, p. 229-31, 2003.

I4. CONTINI, C.; SERACENI, S.; CULTRERA, R. Different PCR systems to detect Toxoplasma gondii tachyzoites or bradyzoites in clinical specimens from patients with and without overt disease. J Eukaryot Microbiol, v. 46, n. 5, p. 77S-78S, 1999

15. COSTA, J. M. et al. Real-time PCR for diagnosis and followup of Toxoplasma reactivation after allogeneic stem cell transplantation using fluorescence resonance energy transfer hybridization probes. J Clin Microbiol, v. 38, n. 8, p. 2929-32, 2000.

16. COUTINHO, S. G. et al. Outbreak of human toxoplasmosis in a rural area. A three-year serologic follow-up study. Mem Inst Oswaldo Cruz, v. 77, n. I, p. 29-36, 1982

17. DAFFOS, F. et al. Prenatal management of 746 pregnancies at risk for congenital toxoplasmosis. N Eng J Med, v. 3।8, n. 5 , p. 27| -5, 1988.

18. DANISE, A. et al. Use of polymerase chain reaction assays of aqueous humor in the differential diagnosis of retinitis in patients infected with human immunodeficiency virus. Clin Infect Dis, v. 24, p. I 100-6, 1997.

19. DECOSTER, A. et al. Detection of anti-Toxoplasma immunoglobulin $A$ antibodies by Platelia-Toxo IgA directed against P30 and by IMx Toxo IgA for diagnosis of acquired and congenital toxoplasmosis. I Clin Microbiol, v. 3, n. 8, p. 2206-8, 1995.

20. DUPON, M. et al. Detection of Toxoplasma gondii by PCR and tissue culture in cerebrospinal fluid and blood of human immunodeficiency virus-seropositive patients. (Clin Microbiol, v. 33, n. 9, p. 2421-6, 1995.

2।. DUPOY-CAMET, J. et al. Detection of Toxoplasma gondii in venous blood from AIDS patients by polymerase chain reaction.J Clin Microbiol, v. 31 , n. 7, p. 1866-9, 1993.

22. ELLIS, J. T. Polymerase chain reaction approaches for the detection of Neospora caninum and Toxoplasma gondii. Int J Parasitol, v. 28, p. 1053-60, 1998.

23. FILICE, G. A. et al. Diagnosis of toxoplasma parasitemia in patients with AIDS by gene detection after amplification with polymerase chain reaction. J Clin Microbiol, v. 31, n. 9, p. 2327-31, 1993.

24. FRANZEN, C. et al. Limited value of PCR for detection of Toxoplasma gondii in blood from human immunodeficiency virus-infected patients. J Clin Microbiol, v. 35, n. I0, p. 2639 4I, 1997.

25. FUENTES, I. et al. Urine sample used for congenital toxoplasmosis diagnosis by PCR.J Clin Microbiol, v. 34, n. I0, p. 2368-7I, 1996.

26. GALVÁN-RAMÍREZ, M. L.; MONDRAGÓN, R. F. Toxoplasmosis humana. Guadalajara: Ediciones Cuellar, 200 I. p. 196.

27. GOZON, G. J. N. et al. Estimation of the avidity of immunoglobulin $G$ for routine diagnosis of chronic Toxoplasma gondii infection in pregnant women. Eur J Clin Microbiol Infect Dis, v. 17, n. I, p. 32-6, 1998

28. $G R O B, U$. et al. Improved sensitivity of de polymerase chain reaction for detection of Toxoplasma gondii in biological and human clinical specimens. Eur J Clin Microbiol Infect Dis, v. I I, n. I, p. 33-9, 1992.

29. GROVER, C. M. et al. Rapid prenatal diagnosis of congenital Toxoplasma infection by using polymerase chain reaction and amniotic fluid. J Clin Microbiol, v. 28, n. 10, p. 2297-30I, 1990.

30. GUAY, J-M. et al. Detection of the pathogenic parasite Toxoplasma gondii by specific amplification of ribosomal sequences using comultiplex polymerase chain reaction. J Clin Microbiol, v. 3 I , n. 2, p. 203-7, 1993.

31. GUY, E. C. et al. Interlaboratory comparison of polymerase chain reaction for the detection of Toxoplasma gondii DNA added to samples of amniotic fluid. EurJ Clin Microbiol Infect Dis, v. 15, p. 836-9, 1996.

32. HILL, D.; DUBEY, J. P.Toxoplasma gondii: transmission, diagnosis and prevention. Clin Microbiol Infect, v. 8, n. 10, p. 634-0, 2002.

33. HITT, J. A.; FILICE, G. A. Detection of Toxoplasma gondii parasitemia by gene amplification, cell culture, and mouse inoculation.J Clin Microbiol, v. 30, n. I2, p. 3181-4, 1992.

34. HODGALL, E. et al. Characterization of Toxoplasma gondii isolates using polymerase chain reaction (PCR) and restriction fragment length polymorphism (RFLP) of the non-coding Toxoplasma gondii (TGR)-gene sequences. Int J Parasitol, v. 30, p. 853-8, 2000

35. HOFFLIN, J. M.; REMINGTON, J. S. Tissue culture isolation of Toxoplasma from blood of a patient with AIDS. Arch Intern Med, v. I45, p. 925-6, 1985.

36. HOHLFELD, P. et al. Prenatal diagnosis of congenital toxoplasmosis with a polymerase-chain-reaction test on amniotic fluid. N Eng J Med, v. 33I, n. I I, p. 695-9, 1994.

37. HOMAN, W. L. et al. Identification of a 200- to 300-fold repetitive 529bp DNA fragment in Toxoplasma gondii, and its use for diagnostic and quantitative PCR. Int J Parasitol, v. 30, p. 69-75, 2000.

38. HO-YEN, D. O. et al. Use of the polymerase chain reaction to detect Toxoplasma gondii in human blood samples. I Clin Pathol, v. 45, p. 910-3, 1992.

39.JAMES, G. S. et al. Comparison of cell culture, mouse inoculation, and PCR for detection of Toxoplasma gondii: effects of storage conditions on sensitivity.J Clin Microbiol, v. 34, n. 6, p. $1572-5,1996$.

40. JOHNSON, J. D. et al. Application of the polymerase chain reaction to the diagnosis of human toxoplasmosis. I Infect, v. 26, p. 147-58, 1993

41.JOSEPH, P. et al. Optimization and evaluation of a PCR assay for detecting toxoplasmic encephalitis in patients with AIDS.J Clin Microbiol, v. 40, n. 12, p. 4499-503, 2002.

42. JOSS, A.W. L. et al. Toxoplasma polymerase chain reaction on experimental blood samples. J Med Microbiol, v. 38, p. 3843, 1993.

43. KHALIFA, K. E. S. et al.Value of PCR for evaluating occurrence of parasitemia in immunocompromised patients with cerebral 
and extracerebral toxoplasmosis.J Clin Microbiol, v. 32, n. I I, p. 28|3-9, 1994.

44. KOMPALIC-CRISTO, A. et al. Lack of technical specificity in the molecular diagnosis of toxoplasmosis. Trans $R$ Soc Trop Med Hyg, v. 98, n. 2, p. 92-5, 2004.

45. KUPFERSCHMIDT, $O$. et al. Quantitative detection of Toxoplasma gondii DNA in human body fluids by TaqMan polymerase chain reaction. Clin Microbiol Infect, v. 7, n. 3, p. |20-4, 200 |.

46. LAMORIL, J. et al. Detection by PCR of Toxoplasma gondii in blood in the diagnosis of cerebral toxoplasmosis in patients with AIDS.J Clin Pathol, v. 49, p. 89-92, 1996.

47. LESER, P. G. et al. A utilização do teste de avidez de lgG para auxiliar a interpretação das reações sorológicas para toxoplasmose com IgM positiva. Rev Soc Bras Med Fetal, v. 5, p. 16-20, 2000.

48. LEBECH, M. et al. Classification system and case definitions of Toxoplasma gondii infection in immunocompetent pregnant women and their congenitally infected offspring. Eur J Clin Microbiol Infect Dis, v. I5, n. I0, p. 799-805, 1996.

49. LUFT, B. J. Toxoplasma gondii. In: WALZER, P. D. et al. (eds.). Parasitic infections in the compromised host. New York: Marcel Dekker, 1989. v. I, p. 179-279.

50. MEI-HUI, L. et al. Real time PCR for quantitative detection of Toxoplasma gondii. J Clin Microbiol, v. 38, n. II, p. 4I2I-5, 2000.

5I. MONTOYA, J. G.; LIESENFELD, O.Toxoplasmosis. Lancet, v. 363, p. 1965-76, 2004.

52. MOZZATTO, L.; PROCIANOY, R. S. Incidence of congenital toxoplasmosis in Southern Brazil: a prospective study. Rev Inst Med Trop Sao Paulo, v. 45, n. 3, p. | 47-5।, 2003.

53. NICOLLE, C.; MANCEAUX, L. Sur une infection a corps de Leishman (ou organismes voisins) du gondi. C R Acad Sci (Paris), v. 147, p. 763-6, 1908.

54. PELLOUX, H. et al. A new set of primers for the detection of Toxoplasma gondii in amniotic fluid using polymerase chain reaction. FEMS Microbiol Lett, v. I 38, p. I I-5, 1996.

55. REITER-OWONA, I. et al.The past and present role of the SabinFeldman dye test in the serodiagnosis of toxoplasmosis. Bull World Health Organ, v. 77, n. II, p. 929-35, 1999.

56. REMINGTON, J. S.; THULLIEZ, P.; MONTOYA, J. G. Recent developments for diagnosis of toxoplamosis.] Clin Microbiol, v. 42, n. 3, p. 94I-945, 2004.

57. REY, L. Parasitologia. 3 ed. Rio de Janeiro: Guanabara Koogan, 2001.

58. ROMAND, S. et al. Usefulness of quantitative polymerase chain reaction in amniotic fluid as early prognostic marker of fetal infection with Toxoplasma gondii. Am J Obstet Gynecol, v. 190, p. 797-802, 2004.

59. ROSSI, C. L. A simple, rapid enzyme-linked immunosorbent assay for evaluating immunoglobulin $G$ antibody avidity in toxoplasmosis. Diagn Microbiol Infect Dis, v. 30, p. 25-30, 1998.

60. ROTH, A. et al. Application of the polymerase chain reaction in the diagnosis of pulmonary toxoplasmosis in immunocompromised patients. Eur J Clin Microbiol Infect Dis, v. II, p. I I77-8I, I992.

6I. SAIKI, R. K. et al. Enzymatic amplification of $\beta$-globin genomic sequences and restriction site analysis for diagnosis of sikle cell anemia. Science, v. 230, p. 1350-4, 1985.

62. SAVVA, D. et al. Polymerase chain reaction for detection of Toxoplasma gondii.J Med Microbiol, v. 32, p. 25-31, 1990.

63. SKINNER, L. J. et al. The use of an IgM immunosorbent agglutination assay to diagnose congenital toxoplasmosis. J Med Microbiol, v. 28, p. 125-8, 1989.

64. SPALDING, S. M. et al. Otimização da reação de polimerase em cadeia para detecção de Toxoplasma gondii em sangue venoso e placenta de gestantes.J Bras Patol Med Lab, v. 38, n. 2, p. 105-10, 2002.

65. SPLENDORE, A. Um nuovo protozoa parassita dei conigli incontrato nelle lesioni anatomiche d'una malattia che ricorda in molti ponti il kala-azar dell'uomo. Rev Soc Sci Sao Paulo, v. 3, p. 109-12, 1908.

66. SUGANE, K. et al. Diagnosis of Toxoplasma meningoencephalitis in a non-AIDS patient using PCR. J Infect, v. 42, n. 2, p. 15960, 2001.

67. TENTER, A.; HECKEROTH, A. R.; WEISS, L. M. Toxoplasma gondii: from animals to humans. Int J Parasitol, v. 30, p. 1217 $58,2000$.

68. VAN de VEN, E. et al. Identification of Toxoplasma gondii infections by $\mathrm{BI}$ gene amplification. J Clin Microbiol, v. 29, n. 10, p. 2120-4, 1991.

69. VERHOFSTEDE, $C$. et al. Polymerase chain reaction in the diagnosis of toxoplasma encephalitis. AIDS, v. 7, n. II, p. |539-4I, 1993.

70. WEISS, J. B. DNA probes and PCR for diagnosis of parasitic infections. Clin Microbiol Rev, v. 8, n. I, p. I I 3-30, 1995.

7I.WEISS, L. M. et al. Sensitive and specific detection of Toxoplasma DNA in an experimental murine model: use of Toxoplasma gondii-specific cDNA and the polymerase chain reaction.J Infect Dis, v. 163, p. 180-6, 1991.

72.WONG, S-Y.; REMINGTON, J. S. Biology of Toxoplasma gondii. AIDS, v. 7, n. 3, p. 299-316, 1993.

73. WONG, S-Y.; REMINGTON, J. S. Toxoplasmosis in pregnancy. Clin Infect Dis, v. I 8, n. 6, p. 853-6I, 1994. 